\title{
Do Journals Publishing in the Field of Urology Endorse Reporting Guidelines? A Survey of Author Instructions
}

\author{
Frank Kunath $^{\mathrm{a}, \mathrm{e}}$ Henrik R. Grobe ${ }^{\mathrm{a}, \mathrm{b}}$ Gerta Rücker ${ }^{c}$ Dirk Engehausen ${ }^{\mathrm{e}}$ \\ Gerd Antes $^{a}$ Bernd Wullich ${ }^{\mathrm{e}}$ Jörg J. Meerpohl ${ }^{\mathrm{a}, \mathrm{d}}$ \\ ${ }^{a}$ German Cochrane Centre, Institute of Medical Biometry and Medical Informatics, ${ }^{b}$ Department of General \\ and Visceral Surgery, ${ }^{C}$ Institute of Medical Biometry and Medical Informatics, and ${ }^{\mathrm{d}}$ Pediatric Hematology and \\ Oncology, Center for Pediatrics and Adolescent Medicine, University Medical Center Freiburg, Freiburg/Br., and \\ eDepartment of Urology, University Clinic Erlangen, Erlangen, Germany
}

\section{Key Words}

Editorial policies · Guideline adherence $\cdot$ Medical standards • Urology

\begin{abstract}
Introduction: Reporting guidelines aim to ensure adequate and complete reporting of clinical studies and are an indispensable tool to translate scientific results into clinical practice. The extent to which reporting guidelines are incorporated into the author instructions of journals publishing in the field of urology remained unclear. Materials and Methods: We assessed the author instructions of uro-nephrological journals indexed in 'Journal Citation Reports 2009'. Two authors independently assessed the author guidelines. We evaluated additional information including whether a journal was published by or in association with a medical association. Discrepancies were resolved by re-checking the respective author instructions and by discussion with a third author. Results: The recommendations of the International Committee of Journal Editors were endorsed by 32 journals (58.2\%) but were mentioned in 12 (37.5\%) only to give general advice about manuscript preparation. Fourteen journals
\end{abstract}

\section{KARGER \\ Fax +41 613061234 E-Mail karger@karger.ch www.karger.com}

(c) 2011 S. Karger AG, Basel

0042-1138/12/0881-0054\$38.00/0

Accessible online at: www.karger.com/uin
(25.5\%) mentioned at least one reporting guideline, with CONSORT the most frequently cited. Journals with high impact factors were more likely to endorse CONSORT ( $p<$ 0.009 ). Other reporting guidelines were mentioned by $<6 \%$ of the journals. Conclusion: All key stakeholders involved in the publication process should more frequently promote the awareness and use of reporting guidelines.

Copyright $\odot 2011$ S. Karger AG, Basel

\section{Introduction}

Clinical studies are a key element of biomedical research and adequate reporting is essential for the translation of findings into clinical practice [1]. Therefore, publications should describe aims, methods, and results in a transparent and complete manner. Deficiencies in the reporting of scientific studies may have serious implications for patients and health systems $[2,3]$. In recent decades, several initiatives have been established to improve this situation.

The International Committee of Medical Journal Editors (ICMJE) was established in 1978 to provide guidance

Frank Kunath, MD

German Cochrane Centre, Institute of Medical Biometry and Medical Informatics University Medical Center Freiburg, Berliner Allee 29

DE-79110 Freiburg/Br. (Germany)

Tel.+497612036715, E-Mail kunath@cochrane.de 
for preparing biomedical manuscripts. A general guideline, Uniform Requirements for Manuscripts Submitted to Biomedical Journals (URM), was published to improve reporting. In addition, ethical principles related to the publication of manuscripts in biomedical journals were incorporated. These requirements addressing authors and reviewers have been revised recently [4].

Over the last 15 years, a number of reporting guidelines for specific study designs have been published to improve the completeness of research reporting $[5,6]$ by specifying a minimum set of information required to understand the trial methodology and to interpret the findings [7]. The first guideline, the CONSORT (CONsolidated Standards Of Reporting Trials) statement, was developed to increase the reporting quality of randomized controlled trials; it was first published in 1996, revised in 2001 , and updated in $2010[8,9]$. Reporting guidelines are also available for various other study designs, including diagnostic test accuracy studies (STAndards for Reporting Diagnostic accuracy, STARD) [10], observational studies (STrengthening the Reporting of OBservational studies in Epidemiology, STROBE) [11], genetic association studies (STrengthening the REporting of Genetic Association studies, STREGA) [12], non-randomized trials (Transparent Reporting of Evaluations with Nonrandomised Designs, TREND) [13], Meta-analysis Of Observational Studies in Epidemiology (MOOSE) [14], and systematic reviews of randomized controlled trials (Preferred Reporting Items for Systematic reviews and Meta-Analyses, PRISMA) [15]. Other reporting guidelines such as COREQ (COnsolidated criteria for REporting Qualitative research) and SQUIRE (Standards for QUality Improvement Reporting Excellence) aim to improve the reporting of qualitative research and quality improvement studies, respectively [16, 17]. In 2008, an international collaboration (Enhancing the QUality And Transparency Of health Research, EQUATOR) was founded to increase the awareness of reporting guidelines, to provide support for their development, and to maintain up-to-date information on health research reporting $[18,19]$. All relevant guidelines are available on the website of the EQUATOR network (www.equatornetwork.org/).

As reporting guidelines are considered helpful tools in ensuring the availability of relevant information in manuscripts, we set out to assess the extent to which references to reporting guidelines are incorporated in the author instructions of journals in the field of urology.

\section{Materials and Methods}

This survey focused on journals relevant to the field of urology. We accessed the 'Journal Citation Reports 2009' [20], identified all journals indexed in the subject categories 'Urology and Nephrology' and 'Andrology' (11/2010), and downloaded author instructions from the journal websites (12/2010). We did not impose any language restrictions.

The author instructions of these journals were analyzed in a two-step approach. First, we checked whether the journals published original research investigations. Journals exclusively reporting commissioned articles or expert reviews were excluded. Journals that ceased publication after 2009 were included only if sufficient information (author instructions) was still available online. If two or more journals referred to the same author instructions, they were treated as independent journals for evaluation.

Second, we evaluated whether the URM or any reporting guidelines were mentioned. If the URM were mentioned, we evaluated the context in which they appeared in the author instructions. If the URM were mentioned only for advice regarding trial registration, conflict of interest, or reference style, we classified its occurrence as 'not relevant'. If the URM were referred to generally or in the context of manuscript preparation, the occurrence was classified as 'relevant'.

We extracted information on the CONSORT [9], STROBE [11], STARD [10], TREND [13], MOOSE [14], PRISMA/QUOROM [15], STREGA [12], COREQ [17], and SQUIRE [16] guidelines, but we also included any other reporting guideline mentioned specifically by the journal. The QUOROM (QUality Of Reporting Of Meta-analyses) guideline was updated and renamed PRISMA in 2009 [15]; for this analysis, we classified QUOROM as a subgroup of PRISMA. We also determined whether author instructions mentioned the EQUATOR network as an additional resource for manuscript preparation. We defined editorial advice on manuscript preparation as any endorsement of reporting guidelines and/or URM in the context of general manuscript preparation.

Two authors (F.K., H.G.) independently read each author guideline and used relevant key words (report, guideline, checklist, CONSORT, STROBE, STARD, MOOSE, PRISMA, QUOROM, TREND, SQUIRE, STREGA, COREQ, international, committee, uniform, EQUATOR) in electronic full-text searches to identify information on the endorsement of the URM and reporting guidelines. One author (F.K.) checked the assessments for discrepancies, which were then resolved by re-checking the respective websites and by discussion with a third author (J.M.).

We retrieved additional information about publication language and country of journals from the database 'Journals in NCBI Databases' in the National Library of Medicine via PubMed $(02 / 2011)$. The information available for the entry 'author(s)' was used to identify whether a journal was the official publication forum of a medical association.

Impact factors of selected journals were compared using the nonparametric Wilcoxon rank-sum test for continuous variables. For the assessment of relationships among endorsement of any reporting guideline or URM, medical associations, publication language, and country of publication, we used a multiple logistic regression model. All statistical tests were two-sided, and $\mathrm{p}<0.05$ was considered significant. 
Table 1. Advice on manuscript preparation (reporting guideline or URM)

\begin{tabular}{|c|c|c|c|c|}
\hline & $\begin{array}{l}\text { All journals } \\
(\mathrm{n}=55)\end{array}$ & $\begin{array}{l}\text { IF } 0.01-2.0 \\
(\mathrm{n}=30)\end{array}$ & $\begin{array}{l}\text { IF 2.01-4.0 } \\
(\mathrm{n}=18)\end{array}$ & $\begin{array}{l}\text { IF }>4.0 \\
(n=7)\end{array}$ \\
\hline \multicolumn{5}{|l|}{ Reference to reporting guidelines } \\
\hline CONSORT & $13(23.6 \%)$ & $4(13.3 \%)$ & $3(16.7 \%)$ & $6(85.7 \%)$ \\
\hline MOOSE & $3(5.5 \%)$ & $1(3.3 \%)$ & $0(-)$ & $2(28.6 \%)$ \\
\hline PRISMA/QUOROM & $3(5.5 \%)$ & $1(3.3 \%)$ & $0(-)$ & $2(28.6 \%)$ \\
\hline STARD & $3(5.5 \%)$ & $1(3.3 \%)$ & $0(-)$ & $2(28.6 \%)$ \\
\hline STROBE & $3(5.5 \%)$ & $1(3.3 \%)$ & $0(-)$ & $2(28.6 \%)$ \\
\hline SQUIRE & $2(3.6 \%)$ & $0(-)$ & $0(-)$ & $2(28.6 \%)$ \\
\hline TREND & $1(1.8 \%)$ & $0(-)$ & $0(-)$ & $1(14.3 \%)$ \\
\hline STREGA & $1(1.8 \%)$ & $0(-)$ & $0(-)$ & $1(14.3 \%)$ \\
\hline COREQ & $1(1.8 \%)$ & $0(-)$ & $0(-)$ & $1(14.3 \%)$ \\
\hline Case report checklist & $1(1.8 \%)$ & $0(-)$ & $0(-)$ & $1(14.3 \%)$ \\
\hline Other guidelines & $1(1.8 \%)$ & $0(-)$ & $0(-)$ & $1(14.3 \%)$ \\
\hline \multicolumn{5}{|l|}{ URM recommendation } \\
\hline URM & $32(58.2 \%)$ & $19(63.3 \%)$ & $8(44.4 \%)$ & $5(71.4 \%)$ \\
\hline General context ('relevant') ${ }^{\mathrm{a}}$ & $12(37.5 \%)$ & $7(36.8 \%)$ & $2(25 \%)$ & $3(60 \%)$ \\
\hline $\begin{array}{l}\text { Context other than general manuscript preparation } \\
\text { ('not relevant') }^{\mathrm{b}}\end{array}$ & $20(62.5 \%)$ & $12(63.2 \%)$ & $6(75 \%)$ & $2(40 \%)$ \\
\hline \multicolumn{5}{|l|}{ Additional resource } \\
\hline EQUATOR network & $1(1.8 \%)$ & $0(-)$ & $0(-)$ & $1(14.3 \%)$ \\
\hline \multicolumn{5}{|l|}{ Advice } \\
\hline Any reporting guideline & $14(25.5 \%)$ & $4(13.3 \%)$ & $3(16.7 \%)$ & $7(100 \%)$ \\
\hline Any reporting guideline or relevant URM & $20(36.4 \%)$ & $8(26.7 \%)$ & $5(27.8 \%)$ & $7(100 \%)$ \\
\hline \multicolumn{5}{|c|}{ 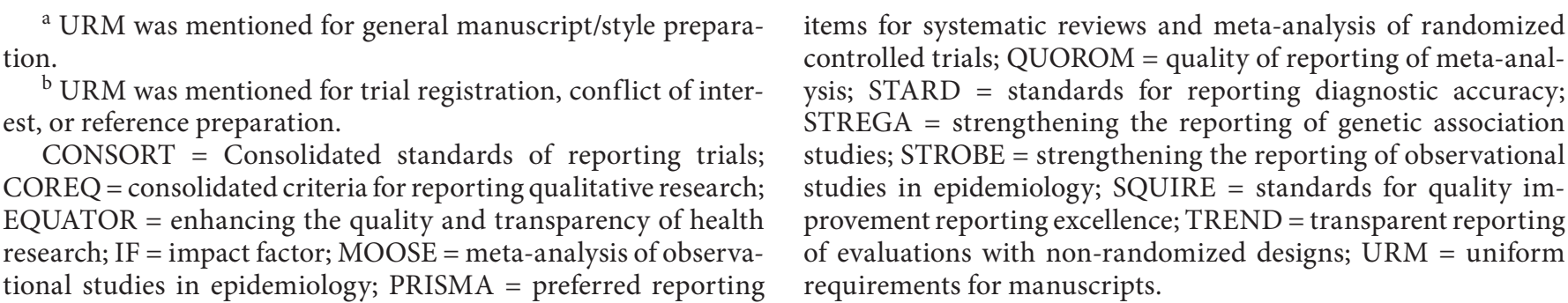 } \\
\hline
\end{tabular}

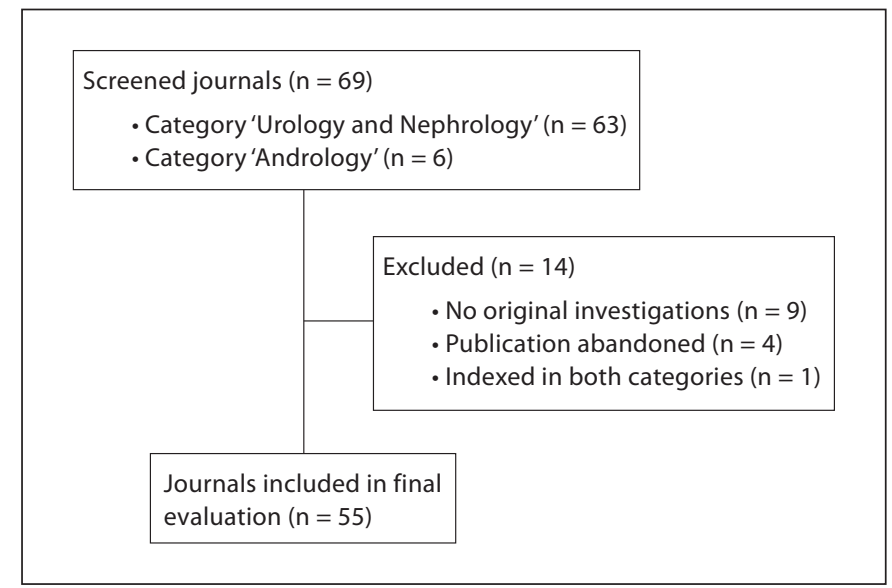

Fig. 1. Selection of research journals.

\section{Results}

We identified 69 journals ('Urology and Nephrology', $\mathrm{n}=63$; 'Andrology', $\mathrm{n}=6$ ), of which 14 journals were excluded (fig. 1) to include 55 journals in the final evaluation. All journals published their editorial scope on their website and offered links to author instructions. The impact factor of the journals ranged from 0.054 to 7.689 .

The recommendations of the ICMJE (URM) were mentioned by 32 journals (58.2\%; table 1 ). However, 20 of these 32 journals (62.5\%) mentioned this guideline exclusively in the context of trial registration, conflict of interest, or style of references ( $\mathrm{n}=4(20 \%), \mathrm{n}=7(35 \%)$, and $n=9$ (45\%), respectively) and were therefore classified as 'not relevant'. Only 12 of the 32 journals (37.5\%) men- 
Table 2. Results of multiple regression analysis of factors potentially associated with advice on manuscript preparation (endorsement of reporting guidelines or URM)

\begin{tabular}{lll}
\hline Variable & $\begin{array}{ll}\text { Odds ratio } \\
(95 \% \mathrm{CI})^{*}\end{array}$ & $\begin{array}{l}\mathrm{p} \\
\text { value }\end{array}$ \\
\hline Intercept & $1.22(0.06-26.08)$ & \\
Medical association vs. nonassociated & $3.00(0.76-11.89)$ & 0.119 \\
English vs. other language & $1.57(0.18-13.88)$ & 0.684 \\
Europe (without UK) vs. other country & $0.09(0.01-1.08)$ & 0.057 \\
UK vs. other country & $0.10(0.01-1.42)$ & 0.088 \\
North America vs. other location & $0.18(0.02-2.19)$ & 0.181 \\
\hline
\end{tabular}

Intercept: Odds for advice on manuscript preparation; other rows: odds ratios.

$\mathrm{URM}=$ Uniform requirements for manuscripts.

tioned the URM in order to give general advice about manuscript preparation and were therefore classified as 'relevant'.

Fourteen journals $(25.5 \%)$ mentioned at least one reporting guideline (table 1), with the CONSORT statement referred to most frequently (13 journals, 92.8\%). Journals with higher impact factors were more likely to endorse the CONSORT statement than journals with lower impact factors $(\mathrm{p}<0.009)$ : six of seven journals $(85.7 \%)$ with impact factors $>4.0$ endorsed the CONSORT statement compared to $13.3-16.7 \%$ of journals with impact factors $<4.0$ (impact factors $2.01-4.0, \mathrm{n}=3,16.7 \%$; impact factors $0.01-2.0, \mathrm{n}=4,13.3 \%)$.

Other reporting guidelines such as MOOSE, PRISMA/QUOROM, STARD, and STROBE were endorsed by only three journals (5.4\%) each, while the checklist SQUIRE was endorsed by two journals (3.6\%). TREND, STREGA, COREQ, and the Case Report Checklist were each endorsed by one journal (1.8\%), as was the EQUATOR network (1.8\%). However, this reference was buried within the reference for the SQUIRE checklist and was not referenced for additional advice on manuscript preparation. One journal mentioned an additional guideline, the 'Analytical reporting checklist for authors', for reporting of animal experiments, cohort studies, or randomized trials. QUOROM was mentioned by one journal despite being obsolete.

Twenty journals (36.4\%) mentioned at least one reporting guideline or the URM in their author instructions (table 1). Of these, 13 journals mentioned the CONSORT statement, six endorsed the URM without mentioning other reporting guidelines, and one journal

Endorsement of Reporting Guidelines in Urology mentioned an additional guideline without referring to the CONSORT statement or the URM. Three journals mentioned more than two reporting guidelines in addition to the URM (range 5-8). All journals with impact factors $>4.0(n=7 ; 100 \%)$ endorsed at least one reporting guideline or the URM, while journals with lower impact factors were more likely to not mention the URM or other reporting guideline (impact factors $2.01-4.0,5 / 18$ journals, $27.8 \%$; impact factors $0.01-2.0,8 / 30$ journals, $26.7 \%$ ). Although the likelihood of endorsement of any reporting guideline seems to increase in parallel with the impact factor of the journal, this trend was not statistically significant (Wilcoxon rank sum test, $\mathrm{p}<0.057$ ).

Thirty-six of 55 journals (65.5\%) were used by medical associations as official publication fora. Of the 20 journals that mention at least one reporting guideline or the URM, 17 (85\%) were associated with at least one medical association. The majority of journals $(\mathrm{n}=48 ; 87.3 \%)$ were published in English, of which 18 endorsed at least one reporting guideline or the URM (37.5\%). Of the remaining seven journals (12.7\%) published in a language other than English (two in German, three in French, two in Spanish), five journals did not mention any reporting guideline (71.4\%). However, the variables included in the exploratory regression model (medical association, publication language, and country of publication) had no statistically significant influence on the endorsement of reporting guidelines or the URM (table 2).

\section{Discussion}

When we analyzed whether the author instructions of journals relevant to urology provided editorial advice about reporting guidelines, we discovered that only $36.4 \%$ of the evaluated journals mentioned at least one reporting guideline or the URM in their author instructions (table 1). The URM was mentioned most often, followed by the CONSORT statement, which was referred to most frequently out of the set of reporting guidelines. Other reporting guidelines were mentioned only rarely. Journals with higher impact factors tended to refer to reporting guidelines more often than journals with lower impact factors.

Previous studies have demonstrated that the trial-reporting quality in the field of urology could be improved [21-23], and that reporting guidelines can improve reporting quality $[5,24,25]$. Our identification of the low proportion of journals endorsing reporting guidelines is in agreement with studies in other specialties. For exam-

Urol Int 2012;88:54-59 
ple, Meerpohl et al. [26] showed that the general endorsement of reporting guidelines was low for pediatric journals; while CONSORT was referenced most frequently (20\% of all selected pediatric journals), all other guidelines were referenced by less than $10 \%$ of those journals. Hopewell et al. [27] evaluated 165 medical journals with high impact factors and determined that CONSORT was mentioned in $38 \%$ of those journals.

It is obvious that authors carry the main responsibility for their manuscripts, and it is their obligation to prepare their research articles in an accurate, transparent, and complete manner so that all the information important for data interpretation is available. However, it cannot be assumed that all authors possess the relevant skills or tools to prepare high-quality articles. We suspect that some authors may not even be aware of reporting guidelines at all. Therefore, and because it is in their own best interest, it seems reasonable to expect journals to refer to reporting guidelines that help ensure good reporting quality. It could be argued that research articles go through peer-review and that this process helps to ensure high scientific quality. However, it is unclear whether the peer-review process is sufficient to guarantee completeness and accuracy of funded research [28] and good reporting quality.

Medical associations promote and coordinate research in their fields and seek to increase the implementation of validated treatments. It was therefore not surprising that $85 \%$ of the journals that endorsed relevant reporting guidelines were used by medical associations as an official publication forum. On the other hand, it was disappointing to observe that only half of all journals used as a publication forum by medical associations endorsed at least one reporting guideline or the URM. It is in the interest of medical associations to ensure high-quality reporting of studies in their affiliated journals and to increase research transparency in general. Medical associations may have the power to influence the editorial policies of affiliated journals and, in our opinion, should request the endorsement of reporting guidelines more frequently and forcefully. Empirical studies have revealed that a requirement for the use of reporting guidelines can increase reporting quality $[5,21]$.

There are some limitations to our study. We know that not all journals in the field of urology are indexed in the 'Journal Citation Reports 2009'. It should therefore be kept in mind that this evaluation is probably not fully representative of all existing urology journals. Assuming that there is a quality gradient for indexed versus nonindexed journals in 'Journals Citation Reports', the overall endorsement of reporting guidelines in the field of urology may even be worse. A further limitation of this study is that we did not assess whether editors or reviewers recommended the guidelines to authors during the submission and/or review processes. However, we assume that this is not a very common practice.

The transparent and complete reporting of research studies is an important cornerstone of knowledge translation. Even an excellently designed and conducted trial is only of limited value if it is inadequately reported. The reporting quality in the field of urology could be increased if more journals endorsed reporting guidelines, which aim to ensure adequate and complete reporting of clinical studies. Aspects of good publication practice such as the use of reporting guidelines have been promoted for years now. However, the uptake and implementation by journals publishing in the field of urology is in general still insufficient. The key stakeholders involved in the publication process should promote the awareness and use of reporting guidelines more comprehensively.

\section{Acknowledgments}

Supported by a Ferdinand Eisenberger grant of the Deutsche Gesellschaft für Urologie (German Society of Urology), grant ID $\mathrm{KuF} 1 / \mathrm{FE}-10$.

\section{References}

1 Antes G: The new consort statement. BMJ 2010;340:c1432.

2 Schunemann HJ, Fretheim A, Oxman AD: Improving the use of research evidence in guideline development. 10. Integrating values and consumer involvement. Health Res Policy Syst 2006;4:22.

3 Oxman AD: Checklists for review articles. BMJ 1994;309:648-651.
4 International Committee of Medical Journal Editors: Uniform requirements for manuscripts submitted to biomedical journals: writing and editing for biomedical publication. www.icmje.org (accessed 06.01.2011).

5 Plint AC, Moher D, Morrison A, Schulz K, Altman DG, Hill C, Gaboury I: Does the consort checklist improve the quality of reports of randomised controlled trials? A systematic review. Med J Aust 2006;185:263267.
6 Smidt N, Rutjes AW, van der Windt DA, Ostelo RW, Bossuyt PM, Reitsma JB, Bouter LM, de Vet HC: The quality of diagnostic accuracy studies since the stard statement: has it improved? Neurology 2006;67:792-797.

7 Simera I, Altman DG: Writing a research article that is 'fit for purpose': EQUATOR network and reporting guidelines. Evid Based Med 2009; 14:132-134. 
8 Moher D, Jones A, Lepage L: Use of the consort statement and quality of reports of randomized trials: a comparative before-andafter evaluation. JAMA 2001;285:1992-1995.

9 Moher D, Hopewell S, Schulz KF, Montori V, Gotzsche PC, Devereaux PJ, Elbourne D, Egger M, Altman DG: Consort 2010 explanation and elaboration: updated guidelines for reporting parallel group randomised trials. BMJ 2010;340:c869.

10 Bossuyt PM, Reitsma JB, Bruns DE, Gatsonis CA, Glasziou PP, Irwig LM, Lijmer JG, Moher D, Rennie D, de Vet HC: Towards complete and accurate reporting of studies of diagnostic accuracy: the STARD initiative. BMJ 2003;326:41-44.

11 von Elm E, Altman DG, Egger M, Pocock SJ, Gotzsche PC, Vandenbroucke JP: The strengthening the reporting of observational studies in epidemiology (STROBE) statement: guidelines for reporting observational studies. Ann Intern Med 2007;147:573-577.

12 Little J, Higgins JP, Ioannidis JP, et al: Strengthening the reporting of genetic association studies (STREGA): an extension of the strobe statement. PLoS Med 2009;6:e22.

13 Des Jarlais DC, Lyles C, Crepaz N: Improving the reporting quality of nonrandomized evaluations of behavioral and public health interventions: the TREND statement. Am J Public Health 2004;94:361-366.
14 Stroup DF, Berlin JA, Morton SC, Olkin I, Williamson GD, Rennie D, Moher D, Becker BJ, Sipe TA, Thacker SB: Meta-analysis of observational studies in epidemiology: a proposal for reporting. Meta-analysis of observational studies in epidemiology (MOOSE) group. JAMA 2000;283:2008-2012.

15 Moher D, Liberati A, Tetzlaff J, Altman DG: Preferred reporting items for systematic reviews and meta-analyses: the PRISMA statement. PLoS Med 2009;6:e1000097.

16 Davidoff F, Batalden P, Stevens D, Ogrinc G, Mooney S: Publication guidelines for improvement studies in health care: evolution of the SQUIRE project. Ann Intern Med 2008;149:670-676.

17 Tong A, Sainsbury P, Craig J: Consolidated criteria for reporting qualitative research (COREQ): a 32-item checklist for interviews and focus groups. Int J Qual Health Care 2007;19:349-357.

18 Altman DG, Simera I, Hoey J, Moher D, Schulz K: Equator: Reporting guidelines for health research. Lancet 2008;371:1149-1150.

19 Simera I, Moher D, Hoey J, Schulz KF, Altman DG: A catalogue of reporting guidelines for health research. Eur J Clin Invest 2010; 40:35-53.

20 ISI Web of Knowledge: Journal Citation Reports. New York, Thomson Reuters, 2011.

21 Mrkobrada M, Thiessen-Philbrook H, Haynes RB, Iansavichus AV, Rehman F, Garg AX: Need for quality improvement in renal systematic reviews. Clin J Am Soc Nephrol 2008;3:1102-1114.

22 Tseng TY, Breau RH, Fesperman SF, Vieweg J, Dahm P: Evaluating the evidence: the methodological and reporting quality of comparative observational studies of surgical interventions in urological publications. BJU Int 2009;103:1026-1031.
23 Welk B, Afshar K, MacNeily AE: Randomized controlled trials in pediatric urology: room for improvement. J Urol 2006;176:306309; discussion 309-310.

24 Devereaux PJ, Manns BJ, Ghali WA, Quan H, Guyatt GH: The reporting of methodological factors in randomized controlled trials and the association with a journal policy to promote adherence to the consolidated standards of reporting trials (CONSORT) checklist. Control Clin Trials 2002;23:380-388.

25 Scales CD Jr, Norris RD, Keitz SA, Peterson BL, Preminger GM, Vieweg J, Dahm P: A critical assessment of the quality of reporting of randomized, controlled trials in the urology literature. J Urol 2007;177:1090-1094; discussion 1094-1095.

26 Meerpohl JJ, Wolff RF, Niemeyer CM, Antes G, von Elm E: Editorial policies of pediatric journals: survey of instructions for authors. Arch Pediatr Adolesc Med 2010;164:268272.

27 Hopewell S, Altman DG, Moher D, Schulz KF: Endorsement of the consort statement by high impact factor medical journals: a survey of journal editors and journal 'instructions to authors'. Trials 2008;9:20.

28 Demicheli V, Di Pietrantoni C: Peer review for improving the quality of grant applications. Cochrane Database Syst Rev 2007;2: MR000003. 